\title{
Zimbabwe: Los métodos de detección de ITR en mujeres no son cost-efectivos
}

Population Council

Follow this and additional works at: https://knowledgecommons.popcouncil.org/departments_sbsr-rh

Part of the Demography, Population, and Ecology Commons, International Public Health Commons, and the Women's Health Commons How does access to this work benefit you? Let us know!

\section{Recommended Citation}

"Zimbabwe: Los métodos de detección de ITR en mujeres no son cost-efectivos," FRONTERAS Resúmenes de Investigación Operativa. Ciudad de México: Population Council, 1999. 


\title{
Zimbabwe Infecciones del tracto \\ Los métodos de detección de ITR en mujeres no son costo-efectivos
} reproductivo

\section{Resumen de 101}

\begin{abstract}
Los métodos existentes de detección de infecciones del tracto reproductivo que se utilizan en usuarias de servicios de planificación familiar no son costo-efectivos: las pruebas de laboratorio son demasiado caras y el manejo sindrómico no es eficaz para descubrir la presencia de todas las infecciones y en ocasiones prescribe tratamientos innecesarios. Los programas de salud deben seguir haciendo hincapié en las medidas preventivas: el cambio de comportamiento individual y la promoción del uso del condón.
\end{abstract}

\section{Antecedentes}

Las infecciones del tracto reproductivo (ITR) son frecuentes en Zimbabwe. Muchas de estas infecciones aumentan el riesgo de contraer el virus de inmunodeficiencia humana (VIH). En 1998, el Consejo Nacional de Planificación Familiar de Zimbabwe (en inglés, ZNFPC) realizó un estudio de IO para evaluar la viabilidad de integrar el diagnóstico y tratamiento de ITR en su oferta de servicios. La población estudiada estaba constituida por 1,634 clientas de tres clínicas de ZNFPC. Se preguntó a las usuarias si presentaban dolor en la región abdominal inferior, flujo vaginal y otros síntomas de ITR; asimismo, se les examinó para detectar la presencia de signos clínicos de este tipo se infecciones y se les practicaron pruebas de laboratorio para confirmar la exactitud del diagnóstico con base en síntomas y signos.

\section{Resultados}

Prevalencia de ITR. Las pruebas de laboratorio revelaron que el 9 por ciento de todas las usuarias servicios de planificación familiar presentaba una o más ITR de transmisión sexual (gonorrea, tricomoniasis y chlamydia). Dichas infecciones acarrean serias consecuencias para la salud pública. La mayoría de las clientas que padece una ITR (26 por ciento del total) presentaba candida o vaginosis bacterial, que no se transmiten sexualmente. Dos terceras partes de las usuarias de PF no presentaron síntomas de las cinco infecciones que se podían detectar mediante las pruebas de laboratorio realizadas.

Aplicación de lineamientos clínicos. Este estudio evaluó el uso de los lineamientos nacionales para el diagnóstico y tratamiento de ITR en sitios donde no se cuenta con pruebas de laboratorio. Estos lineamientos, conocidos como de "manejo sindrómico", instruyen a los proveedores para que traten con medicamentos todas las causas comunes del síndrome específico o la combinación de síntomas reportados por las usuarias, así como los signos clínicos observados durante el examen pélvico. La detección del ITR con base en dichos lineamientos no fue eficaz debido a que:

$\diamond$ Los síntomas no se correlacionaban adecuadamente con las ITR. Más de una tercera parte de las usuarias que padecían una o más ITR (que se detectaron mediante pruebas de laboratorio) fue asintomática, por consiguiente, la infección no se pudo detectar mediante el enfoque sindrómico. En contraste, el 47 por ciento de las clientas de planificación familiar que presentaba síntomas y signos clínicos de ITR, y que por tanto fueron diagnosticadas como infectadas mediante el manejo sindrómico, no padecía en realidad ninguna de las cinco ITR que se podían detectar mediante las pruebas de laboratorio realizadas.

$\diamond$ Los proveedores de servicios no siempre se apegaron a los lineamientos del manejo sindrómico. Únicamente dieron tratamiento al 53 por ciento de las mujeres que padecían dolor en la región abdominal inferior y al 65 por ciento de las que reportaron flujo 
vaginal y que presentaron síntomas clínicos de dicho flujo (algunas de ellas de hecho no padecían infección alguna y no requerían tratamiento). El resto de las mujeres no recibió tratamiento.

Costo de las intervenciones. Ninguna de las intervenciones estudiadas es costeable para los programas que cuentan con pocos recursos. $\mathrm{La}$ intervención de menor costo es el uso del manejo sindrómico para la valoración de aquellas usuarias de PF que solicitan atención de ITR únicamente (véase Tabla 1). Sin embargo, esta intervención tiene sus desventajas. En el estudio realizado, el 75 por ciento de los casos de ITR no se detectaron y al 56 por ciento de las mujeres que recibieron tratamiento, se les clasificó erróneamente como infectadas y, por tanto, recibieron tratamiento innecesario. Las pruebas de laboratorio ofrecen un diagnóstico exacto, pero son muy costosas.

\section{Implicaciones normativas}

La mayoría de los ministerios de salud de países en vías de desarrollo carece de los recursos necesarios para implantar el manejo sindrómico de ITR a gran escala. Por ejemplo, en Zimbabwe, el gasto per capita estimado para la atención a la salud era de US \$47 en 1998. Aplicar el manejo sindrómico de este tipo de infecciones a todas las usuarias de PF absorbería más de 10 por ciento de estos recursos escasos.

La ineficacia del enfoque sindrómico para identificar a las mujeres con ITR requiere de un esfuerzo más organizado para promover y apoyar el desarrollo de pruebas de laboratorio más sencillas y costo-efectivas.

A falta de opciones más costo-efectivas para el manejo de ITR, el ZNFPC y otras organizaciones de salud necesitan reforzar las medidas que reduzcan el sexo inseguro y sin protección, incluyendo la promoción del uso del condón y la consejería para ampliar la percepción de las usuarias acerca del riesgo personal y sus conocimientos sobre prácticas más seguras.

\section{Tabla 1. Precisión y costo de cuatro modelos de diagnóstico de ITR para usuarias de PF

\begin{tabular}{lcccc}
\hline Modelo de diagnóstico & $\begin{array}{c}\text { Núm. de mujeres } \\
\text { que recibió } \\
\text { tratamiento correcto }\end{array}$ & $\begin{array}{c}\text { Núm. de mujeres } \\
\text { que recibió } \\
\text { medicamentos } \\
\text { innecesariamente }\end{array}$ & $\begin{array}{c}\text { Costo total } \\
\text { de medicamentos } \\
\text { y pruebas de } \\
\text { laboratorio (US\$) }\end{array}$ & $\begin{array}{c}\text { Costo por } \\
\text { cliente (US\$) }\end{array}$ \\
\hline
\end{tabular}

Enfoque sindrómico para clientas

de PF que solicitaron atención

para ITR $(n=410)$

130

168

4,024

2.48

Enfoque sindrómico para todas

las usuarias de PF

337

298

8,605

5.30

Enfoque sindrómico para todas las

usuarias de PF, incluyendo pruebas

de laboratorio para clientas con síntomas

y signos clínicos de ITR

337

0

6,722

10.30

Pruebas de laboratorio para todas

las usuarias de $\mathrm{PF}$

524

0

41,819

25.77

Zimbabwe National Family Planning Council. 1999. Demand for and Cost-Effectiveness of Integrating RTI/HIV Services with Clinicbased FP Services in Zimbabwe. Para obtener más información escriba o llame a: Population Council-Oficina Regional para América Latina y el Caribe. Escondida 110, Villa Coyoacán, 04000, México, D.F. México. Tel. (52) 55-54-03-88; Fax: (52) 55-54-12-26. Correo electrónico: disemina@popcouncil.org.mx.

Este proyecto fue posible gracias al apoyo de la Agencia de los Estados Unidos para el Desarrollo Internacional (USAID) bajo el contrato número CCP-3030-C-00-3008-00 y el Acuerdo de Cooperación número HRN-A-00-98-00012-00

\section{Population Council}

